OPEN ACCESS

Edited by:

Paolo Ragonese,

University of Palermo, Italy

Reviewed by:

Smit Patel,

UCLA Health System, United States

Wen-Jun Tu,

Chinese Academy of Medical

Sciences and Peking Union Medical

College, China

*Correspondence:

Peter Waweru

pwaweru09@gmail.com

Specialty section: This article was submitted to

Neuroepidemiology,

a section of the journal

Frontiers in Neurology

Received: 07 October 2021 Accepted: 22 November 2021

Published: 16 December 2021

Citation:

Waweru P and Gatimu SM (2021) Stroke Epidemiology, Care, and Outcomes in Kenya: A Scoping Review. Front. Neurol. 12:785607.

doi: 10.3389/fneur.2021.785607

\section{Stroke Epidemiology, Care, and Outcomes in Kenya: A Scoping Review}

\author{
Peter Waweru ${ }^{1 *}$ and Samwel Maina Gatimu ${ }^{2}$ \\ ${ }^{1}$ Department of Neurosurgery, Kenyatta University Teaching, Referral and Research Hospital, Nairobi, Kenya, ${ }^{2}$ Diabetic Foot \\ Foundation of Kenya, Nairobi, Kenya
}

Background: Stroke is a leading cause of death and disability in sub-Saharan Africa with increasing incidence. In Kenya, it is a neglected condition with a paucity of evidence despite its need for urgent care and hefty economic burden. Therefore, we reviewed studies on stroke epidemiology, care, and outcomes in Kenya to highlight existing evidence and gaps on stroke in Kenya.

Methods: We reviewed all published studies on epidemiology, care, and outcomes of stroke in Kenya between 1 January 1990 to 31 December 2020 from PubMed, Web of Science, EBSCOhost, Scopus, and African journal online. We excluded case reports, reviews, and commentaries. We used the Newcastle-Ottawa scale adapted for cross-sectional studies to assess the quality of included studies.

Results: Twelve articles were reviewed after excluding 111 duplicates and 94 articles that did not meet the inclusion criteria. Five studies were of low quality, two of medium quality, and five of high quality. All studies were hospital-based and conducted between 2003 and 2017. Of the included studies, six were prospective and five were single-center. Stroke patients in the studies were predominantly female, in their seventh decade with systemic hypertension. The mortality rate ranged from 5 to $27 \%$ in-hospital and 23.4 to $26.7 \%$ in 1 month.

Conclusions: Our study highlights that stroke is a significant problem in Kenya, but current evidence is of low quality and limited in guiding policy development and improving stroke care. There is thus a need for increased investment in hospital- and community-based stroke care and research.

Keywords: stroke, Kenya, sub-Saharan Africa, Africa, East Africa

\section{INTRODUCTION}

Sub-Saharan Africa (SSA) has the highest stroke burden globally with a steadily increasing incidence estimated at 316 cases per 100,000 persons (1-4). Stroke in SSA occurs in relatively young patients and tends to be severe due to uncontrolled risk factors (5); resulting in high personal and societal costs (6) and significant disability (3).

While significant progress has been made in stroke care in high-income countries, stroke care in SSA is disjointed with glaring gaps in all areas of the stroke care continuum (7). This is due to poor health infrastructure, shortage of specialists, poor health financing models, lack of 
and poor implementation of health policies and resources, and poor leadership and governance that characterize most health systems in SSA (8). Consequently, specialized stroke care-from prehospital, hyperacute and acute stroke care, to rehabilitation and secondary prevention-is markedly underdeveloped (6) resulting in high morbidity and mortality (9-11).

Stroke in Kenya is a neglected condition despite the urgent care stroke patients need. Most stroke patients are managed in general wards by non-neurologists and clinical officers (the equivalent of physician assistants) with minimal training in stroke care. In addition, stroke patients are usually referred to private diagnostic facilities for neuroimaging due to breakdown and/or lack of scanners, which are only available in $13 \%$ of health facilities (12) adding to the financial burden of stroke. These highlight far-reaching gaps in stroke care in Kenya; the extent to which is not well known. Thus, we aimed to collate studies on epidemiology, care, and outcomes of stroke in Kenya to guide further action in stroke research, policy, and care.

\section{METHODS}

We conducted a systematic scoping review of all studies reporting on stroke in Kenya. The Preferred Reporting Items for Systematic Reviews and Meta-Analyses for Scoping Review (PRISMA-SR) guided the conduct and reporting of this review (Supplementary Table 1).

First, two reviewers performed a comprehensive search in the following databases: EBSCOhost, PubMed, Web of Science, Scopus, Africa Journal Online (AJOL) and Google Scholar. Reference lists of included studies and Kenyan universities' repositories were also searched. The search terms included "stroke" OR "cerebrovascular accident" OR "CVA" OR "cerebrovascular event" OR "CVE" OR "transient ischemic attack" OR "TIA" OR "brain hemorrhage" OR "hemorrhagic stroke” OR "ischemic stroke" AND "Kenya."

Second, all identified studies were imported to the Endnote (x8) reference manager for removal of duplicates and further review. Third, one reviewer (PW) read the titles and abstracts of records obtained through the electronic searches and excluded irrelevant studies. Fourth, full texts of the remaining studies were obtained, and two reviewers (PW and SMG) read the full text and independently selected studies for inclusion based on the following eligibility criteria:

- Study design: Community- and hospital-based observational and experimental studies.

- Study setting: Conducted in Kenya.

- Outcome: Stroke incidence, prevalence, subtypes, risk factors, recognition and response, imaging and laboratory investigations, thrombolysis or thrombectomy, inpatient care, neurorehabilitation and post-stroke care, secondary prevention, short or long-term outcomes (mortality and functional, psychiatric, and neurocognitive outcomes), quality of life and cost of stroke.

- Participants: Adult stroke patients or stroke care providers.

- Timelines: 1 January 1990 and 31 December 2020.
We excluded studies with no full text, review articles, case reports and commentaries, and unpublished theses and dissertations.

The reviewers independently assessed the quality of the included studies using the "Newcastle-Ottawa Quality Assessment Scale" adapted for cross-sectional studies (13). In cases where the reviewers could not agree, an average quality score was computed.

The two review authors independently extracted data from the included studies using a standard data extraction form and entered it in Microsoft Excel. We compared the extracted data for accuracy and consistency and agreed through discussion on any inconsistencies before summarizing them in the results section (Table 1).

\section{RESULTS}

Of the 217 articles identified from a database search as well as a search of grey literature, 111 duplicates were removed. Nineteen full texts were screened for eligibility and 12 articles were included (Figure 1).

\section{Characteristics of Included Studies}

Table 1 highlights the characteristics of the included studies. Twelve hospital-based studies conducted between 2003 and 2017 met the inclusion criteria (14-25). Six studies were retrospective $(14,19-21,23,25)$ while six were prospective $(15-18,22,24)$. One study was conducted in a rural hospital (18), and one in a private hospital (19). Five studies were single-center (14, 18, $19,21,24)$ while seven were multicenter $(15-17,20,22,23,25)$. One study included only cortical ischemic stroke patients (21) while one other study included only patients with chronic (over two months) strokes aged 15-49 years (20). Only one study on subarachnoid hemorrhage patients was included (25).

\section{Quality Assessment of Included Studies}

Five studies were of low quality, two of medium quality and five of high quality (Supplementary Table 2). Six studies were not representative, five had poorly calculated or unexplained sample sizes, seven studies did not control for confounders and seven studies did not perform the appropriate statistical tests.

\section{Epidemiology of Stroke in Kenya}

The incidence and prevalence of stroke in Kenya remain largely unknown. There was a varied point prevalence of stroke in three hospital-based studies: $0.6 \%$ in a referral hospital in Western Kenya (14), 3.0\% in an urban private hospital in Nairobi (19) and $7.1 \%$ in a rural hospital in Eastern Kenya (18). Most stroke cases were ischemic (48-85\%), with the proportion of hemorrhagic strokes ranging from 8.8 to $52 \%(14-16,19)$. The rate of stroke recurrence was $15 \%$ in two studies based in tertiary referral centers $(14,15)$ and $20 \%$ in a rural hospital-based study (18).

Overall, stroke peaked in the seventh decade $(15,16,18)$ with a mean age of 58.6 in a prospective multicenter referral hospitalbased study (16), 61.3 years in a Nairobi-based private hospital (19) and 68.8 years in a rural hospital (18). There was a female predominance among stroke patients in most studies with the highest proportion of female stroke patients being in the rural 
TABLE 1 | Characteristics of included studies.

\begin{tabular}{|c|c|c|c|c|c|c|c|c|c|c|c|c|c|}
\hline References & Title & $\begin{array}{c}\text { Year of } \\
\text { publication }\end{array}$ & $\begin{array}{l}\text { Year(s) of } \\
\text { study }\end{array}$ & Design & Setting & Study population & Case definition & $\begin{array}{c}\% \text { of stroke } \\
\text { cases confirmed } \\
\text { by neuroimaging }\end{array}$ & $n$ & $\begin{array}{l}\text { Mean age } \\
\text { (SD) }\end{array}$ & $\begin{array}{l}\text { Peak age, } \\
\text { years }^{\star \star}\end{array}$ & $\begin{array}{c}\text { Female } \\
\%\end{array}$ & $\begin{array}{c}\text { HS } \\
\%\end{array}$ \\
\hline $\begin{array}{l}\text { Oduor et al. } \\
\text { (14) }\end{array}$ & $\begin{array}{l}\text { Stroke types, risk } \\
\text { factors, quality of care } \\
\text { and outcomes at a } \\
\text { Referral Hospital in } \\
\text { Western, Kenya }\end{array}$ & 2015 & 2010-2014 & Retrospective & Urban/Public & $\begin{array}{l}\text { All strokes, } \geq 18 \\
\text { years }\end{array}$ & $\begin{array}{l}\text { WHO definition of } \\
\text { stroke }\end{array}$ & 100 & 155 & $61(49-72)^{\star}$ & $>69$ & 58 & 52 \\
\hline $\begin{array}{l}\text { Kaduka et al. } \\
\text { (15) }\end{array}$ & $\begin{array}{l}\text { Stroke distribution } \\
\text { patterns and } \\
\text { characteristics in } \\
\text { Kenya's leading public } \\
\text { health tertiary } \\
\text { institutions: Kenyatta } \\
\text { National Hospital and } \\
\text { Moi Teaching and } \\
\text { Referral Hospital }\end{array}$ & 2018 & 2015-2016 & Prospective & Urban/Public & $\begin{array}{l}\text { All strokes, } \geq 18 \\
\text { years }\end{array}$ & $\begin{array}{l}\text { CT/MRI confirmed } \\
\text { stroke }\end{array}$ & 100 & 691 & $60(45-73)^{*}$ & $60-69$ & 57.5 & 44.4 \\
\hline $\begin{array}{l}\text { Kaduka et al. } \\
\text { (16) }\end{array}$ & $\begin{array}{l}\text { Stroke mortality in } \\
\text { Kenya's Public Tertiary } \\
\text { Hospitals: a } \\
\text { prospective } \\
\text { facility-based study }\end{array}$ & 2018 & 2015-2016 & Prospective & Urban/Public & $\begin{array}{l}\text { All strokes, } \geq 18 \\
\text { years }\end{array}$ & $\begin{array}{l}\text { CT/MRI confirmed } \\
\text { stroke }\end{array}$ & 100 & 719 & $58.6(18.7)$ & $60-69$ & 56.7 & 43.9 \\
\hline $\begin{array}{l}\text { Kaduka et al. } \\
\text { (17) }\end{array}$ & $\begin{array}{l}\text { Disability-adjusted } \\
\text { life-years due to stroke } \\
\text { in Kenya }\end{array}$ & 2019 & 2015-2016 & Prospective & Urban/Public & $\begin{array}{l}\text { All strokes, } \geq 18 \\
\text { years }\end{array}$ & $\begin{array}{l}\text { CT/MR confirmed } \\
\text { stroke }\end{array}$ & 100 & 719 & $58.6(18.7)$ & $60-64$ & 56.7 & 43.9 \\
\hline $\begin{array}{l}\text { Ominde et al. } \\
\text { (18) }\end{array}$ & $\begin{array}{l}\text { Pattern of stroke in a } \\
\text { rural Kenyan hospital }\end{array}$ & 2019 & 2015-2016 & Prospective & Rural/Public & All strokes, Adults & $\begin{array}{l}\text { WHO definition of } \\
\text { stroke }\end{array}$ & 100 & 227 & $68.8(6.8)$ & $60-69$ & 62 & 32.6 \\
\hline $\begin{array}{l}\text { Jowi et al. } \\
\text { (19) }\end{array}$ & $\begin{array}{l}\text { Pathological sub-types, } \\
\text { risk factors and } \\
\text { outcome of stroke at } \\
\text { the Nairobi Hospital, } \\
\text { Kenya }\end{array}$ & 2009 & 2003-2006 & Retrospective & $\begin{array}{l}\text { Urban/ } \\
\text { Private }\end{array}$ & $\begin{array}{l}\text { All strokes, } \geq 18 \\
\text { years }\end{array}$ & $\begin{array}{l}\text { WHO definition of } \\
\text { stroke }\end{array}$ & 100 & 80 & 61.3 & - & 46.2 & 8.8 \\
\hline $\begin{array}{l}\text { Muli et al. } \\
\text { (20) }\end{array}$ & $\begin{array}{l}\text { Quality of life amongst } \\
\text { young adults with } \\
\text { stroke living in Kenya }\end{array}$ & 2013 & $2007-2008$ & Retrospective & Urban/ Public & $15-49$ years & Not defined & - & 161 & - & $40-49$ & 55.9 & - \\
\hline $\begin{array}{l}\text { Ogengo and } \\
\text { Olabu (21) }\end{array}$ & $\begin{array}{l}\text { Ischemic cortical stroke } \\
\text { in a Kenyan Referral } \\
\text { Hospital }\end{array}$ & 2015 & $2007-2011$ & Retrospective & Urban/ Public & $\begin{array}{l}\text { Cortical, ischemic } \\
\text { strokes, } \geq 18 \text { years }\end{array}$ & $\begin{array}{l}\text { Paralysis, aphasia, } \\
\text { and headache } \\
\text { combined with CT } \\
\text { scan and } \\
\text { angiographic } \\
\text { findings. }\end{array}$ & 100 & 377 & $54.72(16.8)$ & - & 54.6 & - \\
\hline
\end{tabular}


TABLE 1 | Continued

\begin{tabular}{|c|c|c|c|c|c|c|c|c|c|c|c|c|c|}
\hline References & Title & $\begin{array}{c}\text { Year of } \\
\text { publication }\end{array}$ & $\begin{array}{c}\text { Year(s) of } \\
\text { study }\end{array}$ & Design & Setting & Study population & Case definition & $\begin{array}{c}\% \text { of stroke } \\
\text { cases confirmed } \\
\text { by neuroimaging }\end{array}$ & $n$ & $\begin{array}{l}\text { Mean age } \\
\text { (SD) }\end{array}$ & $\begin{array}{c}\text { Peak age, } \\
\text { years }\end{array}$ & $\begin{array}{c}\text { Female } \\
\%\end{array}$ & $\begin{array}{c}\text { HS } \\
\%\end{array}$ \\
\hline $\begin{array}{l}\text { Ogolla and } \\
\text { Opemo (22) }\end{array}$ & $\begin{array}{l}\text { Early mobilization and } \\
\text { physical activity } \\
\text { improve stroke } \\
\text { recovery: a cohort } \\
\text { study of stroke } \\
\text { inpatients in Kisumu } \\
\text { County Referral } \\
\text { Hospitals, Kenya }\end{array}$ & 2016 & 2015 & Prospective & Urban & $\begin{array}{l}\text { All strokes, } \geq 18 \\
\text { years }\end{array}$ & Not defined & - & 100 & $59.1(2.3)$ & - & 61 & - \\
\hline $\begin{array}{l}\text { Wanjiru } \\
\text { Kingau (23) }\end{array}$ & $\begin{array}{l}\text { Care process for stroke } \\
\text { patients in Kenya: } \\
\text { mixed study }\end{array}$ & 2018 & 2014 & Retrospective & $\begin{array}{l}\text { Urban-Rural/ } \\
\text { Public }\end{array}$ & All strokes, Adults & Not defined & - & 150 & $61.7(16.7)$ & - & 36.5 & - \\
\hline $\begin{array}{l}\text { Wairoto et al. } \\
\text { (24) }\end{array}$ & $\begin{array}{l}\text { Prevalence and nature } \\
\text { of psychiatric morbidity } \\
\text { in stroke outpatients in } \\
\text { Kenyatta national } \\
\text { hospital, Kenya }\end{array}$ & 2020 & 2015 & Prospective & Urban & $\begin{array}{l}\text { All strokes, } \geq 18 \\
\text { years }\end{array}$ & Not defined & - & 210 & - & - & 41 & - \\
\hline $\begin{array}{l}\text { Waweru and } \\
\text { Gatimu (25) }\end{array}$ & $\begin{array}{l}\text { Mortality and functional } \\
\text { outcomes after a } \\
\text { spontaneous } \\
\text { subarachnoid } \\
\text { hemorrhage: A } \\
\text { retrospective } \\
\text { multicenter } \\
\text { cross-sectional study in } \\
\text { Kenya }\end{array}$ & 2019 & 2009-2017 & Retrospective & Urban & $\mathrm{SAH}, \geq 18$ years & $\begin{array}{l}\text { Suggestive } \\
\text { presentation } \\
\text { supported by } \\
\text { computed } \\
\text { tomography, } \\
\text { lumbar puncture, } \\
\text { or necropsy } \\
\text { evidence of SAH }\end{array}$ & 100 & 158 & 48.6 (15.9) & - & 57.6 & All \\
\hline
\end{tabular}

HS, haemorrhagic stroke; SAH, subarachnoid hemorrhage.

${ }^{*}$ Median (IQR); **Range. 


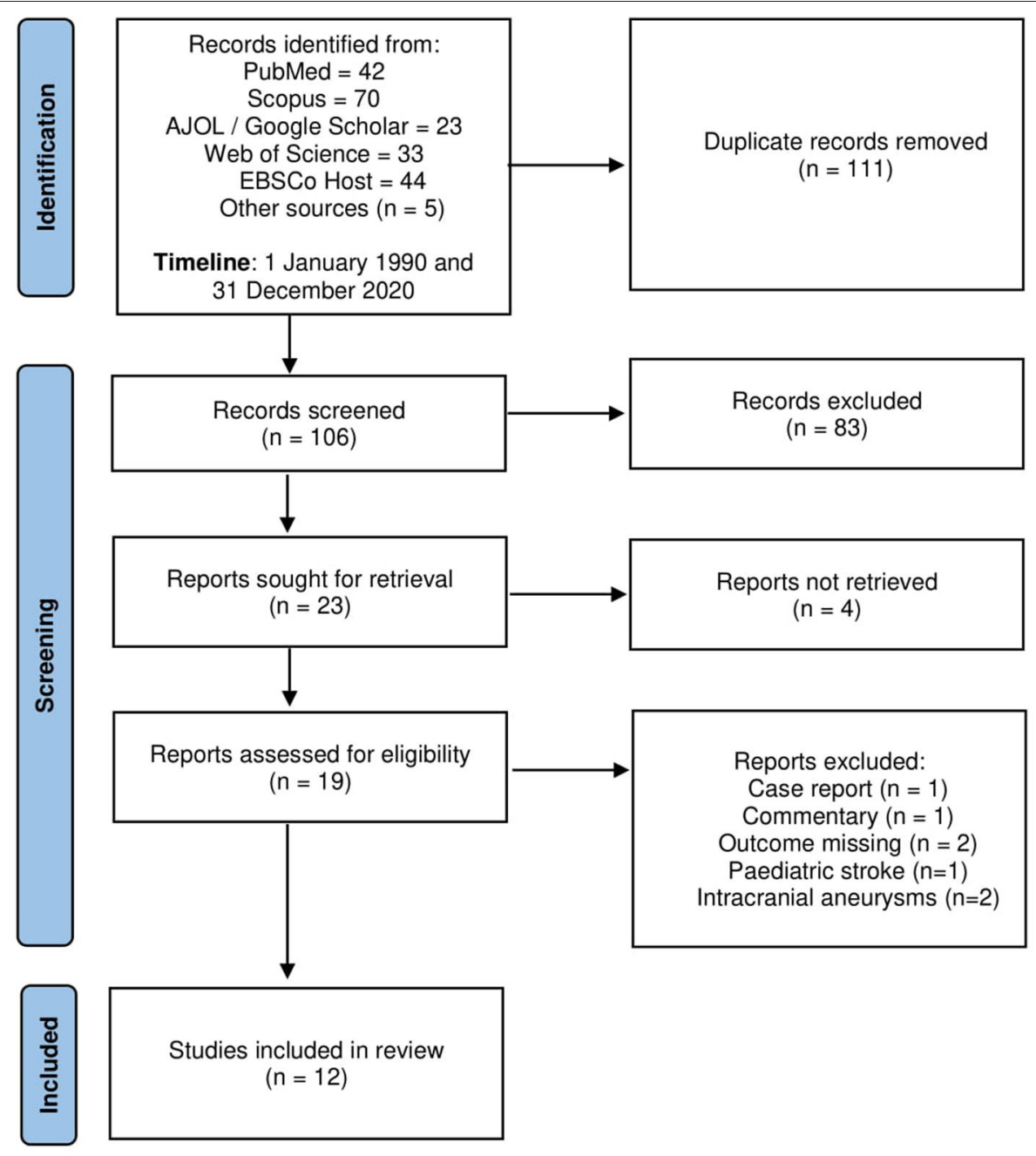

FIGURE 1 | PRISMA flow chart of selected studies.

hospital (62\%) (18). Besides age and sex, other major risk factors of stroke included hypertension (50-80\%), diabetes (4-32.5\%) and human immunodeficiency virus (HIV) infection (2.5-12\%) (Table 2).

SAH was commonest in females (58\%) with a mean age of 48.6 (SD 15.9); a majority (62\%) being aneurysmal SAH (aSAH) although only $58 \%$ of all patients had cerebral angiography (25).

\section{Stroke Care and Outcomes}

Very limited data was found on the quality and access of stroke care services in the country. Only one study (14) described quality parameters for stroke care including the time from stroke onset to a presentation [median: 2 days (IQR: 1-3 days)], stroke severity assessment ( $92 \%$ by Glasgow coma scale), provision of antithrombotic within $48 \mathrm{~h}(73 \%)$, ambulation within $48 \mathrm{~h}$ (33\%), thromboprophylaxis (24\%), smoking cessation counseling (25\%) and dysphagia screening before oral intake (3\%). Vascular imaging for ischemic stroke via carotid doppler imaging is more common in private/urban hospitals, but even then was only $40 \%$ in a private hospital study (19). Even less data was available on stroke rehabilitation (22) with only one low-quality study reporting on inpatient physiotherapy (23). Secondary prevention was also very basic with only two-thirds of patients discharged on antithrombotic drugs (14).

In-hospital mortality in public hospitals ranged from 21.6 to $27 \%(14,16)$ while it was only $5 \%$ in a private hospital $(19)$. About a quarter of stroke patients died in 1 month (23.4-26.7\%); and about a third $(29.8-34.1 \%)$ in 3 months $(15,16)$. Stroke mortality was associated with age (higher in older patients), sex (higher in females) and stroke type (higher in ischemic stroke overall at 12 months but higher in hemorrhagic stroke at 1 month) (16). In aSAH patients, only half of the patients had surgical or endovascular management, and this was delayed for up to 20 days after presentation, especially in public hospitals. Consequently, a quarter of patients with SAH died in hospitals, and less than half (46\%) had favorable functional outcomes on follow-up (25).

No studies described cognitive outcomes. One low-quality study reported on the psychiatric outcomes (24); with a third 
TABLE 2 | Risk factors and outcomes of stroke in Kenya.

\begin{tabular}{|c|c|c|c|c|c|c|c|c|c|c|c|c|c|c|}
\hline \multirow[t]{2}{*}{ References } & \multirow[t]{2}{*}{$\mathbf{n}$} & \multicolumn{7}{|c|}{ Risk factors } & \multirow{2}{*}{$\begin{array}{l}\text { In-hospital } \\
\text { deaths \% }\end{array}$} & \multicolumn{5}{|c|}{ Dead/Lost to follow-up (\%) $)^{\S}$} \\
\hline & & $\begin{array}{c}\text { HTN } \\
\%\end{array}$ & DM\% & $\begin{array}{c}\text { Smoking } \\
\%\end{array}$ & $\begin{array}{c}\text { Alcohol } \\
\%\end{array}$ & $\begin{array}{l}\text { Previous } \\
\text { stroke \% }\end{array}$ & $\begin{array}{c}\text { Hypercholesterolemia } \\
\%\end{array}$ & $\begin{array}{c}\text { HIV } \\
\%\end{array}$ & & 10 days & 28-days & $\begin{array}{c}90 \\
\text { days }\end{array}$ & $\begin{array}{c}180 \\
\text { days }\end{array}$ & 1 year \\
\hline $\begin{array}{l}\text { Jowi and } \\
\text { Mativo (19) }\end{array}$ & 80 & 80 & 32.5 & - & - & - & $36.5^{\star}$ & 2.5 & 5 & - & - & - & - & - \\
\hline $\begin{array}{l}\text { Kaduka et al. } \\
\text { (15) }\end{array}$ & 691 & 77.3 & 14.9 & 16.1 & & 15.4 & $2.8^{\star \star}$ & 8 & & $\begin{array}{l}16.4 \\
(4.2)\end{array}$ & $\begin{array}{l}23.4 \\
(7.8)\end{array}$ & $\begin{array}{l}29.8 \\
(21)\end{array}$ & $\begin{array}{c}32 \\
(38.2)\end{array}$ & \\
\hline $\begin{array}{l}\text { Ominde et al. } \\
\text { (18) }\end{array}$ & 227 & 74 & 32 & 48 & 63 & 20 & - & 12 & - & - & - & - & - & - \\
\hline $\begin{array}{l}\text { Oduor et al. } \\
\text { (14) }\end{array}$ & 155 & 73 & 4 & 9 & 24 & 15 & $84^{\dagger}$ & 10 & 27 & - & - & - & - & - \\
\hline $\begin{array}{l}\text { Kaduka et al. } \\
\text { (16) }\end{array}$ & 719 & - & - & - & - & - & - & - & 21.6 & $\begin{array}{l}18.4 \\
(1.3)\end{array}$ & $\begin{array}{l}26.7 \\
(1.7)\end{array}$ & $\begin{array}{l}34.1 \\
(22.1)\end{array}$ & $\begin{array}{l}37.8 \\
(22.9)\end{array}$ & $\begin{array}{l}41.7 \\
(26.1)\end{array}$ \\
\hline $\begin{array}{l}\text { Waweru and } \\
\text { Gatimu (25) }\end{array}$ & 158 & 50 & - & 14.2 & 25.4 & - & - & - & 24.1 & - & 26.6 & - & - & - \\
\hline
\end{tabular}

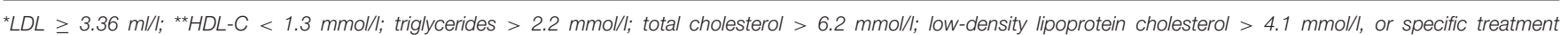
for hypercholesterolemia.

† Elevated plasma total cholesterol levels of $>5.18$ mmol/l or LDL cholesterol levels $>2.6$ mmol// or HDL levels < $1.3 \mathrm{mmol} / \mathrm{l}$, or had been using lipid-lowering medication.

${ }^{\S}$ Percentage of patients lost to follow-up in brackets; HTN, hypertension; DM, diabetes mellitus.

of stroke patients having some psychiatric morbidity; majorly depression (19\%) and general anxiety disorder (9.5\%).

\section{DISCUSSION}

Evidently, little is known about stroke in Kenya. Current literature on stroke epidemiology, stroke care and post-stroke outcomes in Kenya is of low-medium quality. From current evidence, stroke in Kenya is of unknown incidence and prevalence, largely affecting patients in their sixth and seventh decades; with an even earlier onset in subarachnoid hemorrhage stroke subtypes; and predominantly affecting female patients, with hypertension being a major risk factor. After a stroke, care is mainly basic and unsurprisingly, outcomes are poor.

In other sub-Saharan Africa studies such as the INTERSTROKE study (5) similar findings have been reported, including the predominance of female stroke patients, younger stroke patients compared to other regions, a higher proportion of hemorrhagic strokes and poorer outcomes.

These findings reflect the neglect stroke patients face in sub-Saharan Africa due to a lack of resources. The female predominance of stroke patients in the region is likely attributable to the hospital-based nature of most of the regional studies. This is further impacted by the fact that most men in the region have poor health-seeking behaviors due to financial incapacity (26), as well as the higher stroke severity in women (27) which would lead to most men with relatively minor strokes opting for alternative therapies that are not uncommon in the region.

In Kenya, primary stroke prevention is underfunded and of limited reach, symbolic of primary health care systems in the region. Consequently, while about a quarter of the Kenyan population is hypertensive (28), only $22.3 \%$ are on treatment and only 3\% have controlled hypertension (29). The bulk of resultant uncontrolled hypertension has been cited as a plausible reason for the higher proportion of hemorrhagic stroke in the region (29-60\%) compared to Western countries $(16-20 \%)(3,5,30,31)$. The difference in the proportion of stroke subtypes has also been attributed to the tendency to scan only stroke patients with more severe strokes in this resource-limited setting, of which hemorrhagic strokes predominate (4).

After a stroke, Kenyan and sub-Saharan Africa stroke patients are faced with many hurdles including delayed transportation due to lack of emergency response systems, ill-equipped hospitals, and lack of stroke specialists (11, 32-34). In Kenya, for instance, only $13 \%$ of health facilities have computed tomography scanners which are so central in stroke diagnosis; and only half of the health facilities have aspirin (12). Worse, only $4 \%$ of health facilities in Kenya offer rehabilitation services, largely physiotherapy with limited speech and occupation therapy (12). Furthermore, Kenya has only eight registered adult neurologists (35) against a population of 50 million persons and a growing burden of stroke. Most of these specialists are in large urban or private hospitals where resources for stroke care are less limited. However, to improve stroke care in Kenya, the government has recently through the Managed Equipment Services equipped most national and county referral hospitals with imaging equipment such as CT scans (36). There is also increased sensitization and enrolment of the population to the National Health Insurance Fund, as a pathway to access to universal healthcare and to reduce the catastrophic health expenditure incurred by patients including stroke patients in the country. Concurrently, the county governments-which oversee health service delivery-have continued to increase investment in the health sector to provide accessible and quality health care. Despite these efforts, stroke is still not a prioritized noncommunicable disease and the country lacks clear national stroke 
prevention, treatment and rehabilitation strategy or policies. For example, the current non-communicable disease strategy 20212025 only tracks an increase in the coverage of hypertensive and diabetes patients receiving drug therapy or counseling from 6.2 to $50 \%$ by 2025 (37).

Unsurprisingly, while about $5 \%$ of stroke patients died in a private hospital (19), this was 4-fold in public hospitals $(15,16)$. Such high mortality post-stroke in SSA has been reported with $<50 \%$ of patients alive at 12 months (30). Similar to our study, about a quarter of stroke patients die within 1 month in the region (38), which is about five times more deaths than in Western countries (5).

Overall, stroke care in Kenya remains suboptimal due to the lack of clear and coordinated stroke prevention and management policies and models of stroke care. However, with the recent focus on universal healthcare, the country could learn and adopt some of the best practices on stroke prevention and models of care from other low resource settings. One such model-the China Stroke Prevention Project Committee (CSPPC) program-aimed to establish prevention and control systems for stroke in China (39). The program improved primary prevention strategies, established stroke centers for the treatment of stroke patients-organized into advanced stroke centers and stroke prevention centers-and established stroke maps for different cities to define timely transport of stroke patients and ensure early treatment (39). A similar model in Kenya would entail stratifying stroke care into basic (primary) stroke care centers tasked with stroke prevention, basic care and neurorehabilitation and advanced/comprehensive stroke centers with capacity of thrombolysis, thrombectomy and neurosurgery. The model could easily be implemented within Kenya's hierarchical health care system; with the county (level 5) and national (level 6) referral hospitals tasked with comprehensive stroke care and lower levels (levels 14) tasked with a timely referral of patients, patient followup, primary and secondary prevention, including communitybased neurorehabilitation. Similarly, transit of patients can be streamlined using a similar "green map" as has been utilized by the CSPPC model in China though the economic models that would allow such a realignment of stroke care and establishment of stroke care models need further research. Moreover, patients' organizations such as the Stroke Association of Kenya could play a pivotal role in creating awareness on stroke and advocating for better models of stroke care in Kenya.

\section{REFERENCES}

1. Boutayeb A, Derouich M, Boutayeb W, Lamlili MEN. Cerebrovascular diseases and associated risk factors in WHO Eastern mediterranean countries. Cardiol Angiol. (2014) 2, 62-75. doi: 10.9734/CA/20 $14 / 9731$

2. Lekoubou A, Nkoke C, Dzudie A, Kengne AP. Stroke admission and case-fatality in an urban medical unit in sub-Saharan Africa: a fourteen year trend study from 1999 to 2012. J Neurol Sci. (2015) 350:2432. doi: 10.1016/j.jns.2015.02.002

\section{LIMITATIONS}

This review maps out and assesses the quality of current evidence on stroke in Kenya using a systematic approach. The study, however, has some limitations. First, only 12 studies met the inclusion criteria of the review; five of which were of low quality. Second, the studies included may have underestimated the burden of stroke in Kenya due to: (i) potential referral bias in hospital-based studies, (ii) incomplete data in retrospective studies and (iii) lack of representativeness in hospital-based and single-centered studies. Only one study was conducted in a rural setting despite two-thirds of the population in Kenya living in rural areas. Third, most studies did not report on aspects of stroke care including hyperacute, inpatient and rehabilitation care, secondary prevention, and functional, neurocognitive, and psychiatric outcomes limiting a better understanding of stroke in Kenya.

\section{CONCLUSION}

This study clearly depicts a dearth of evidence on stroke in Kenya, a trend evident in other SSA countries. Similar to other studies in the region, stroke is common in females, occurs at a relatively younger age and has poor outcomes owing to lack of quality care, especially among patients in public hospitals. Current evidence is limited in guiding policy development and improving stroke care in Kenya. There is a need for increased investment in hospitaland community-based stroke care and research. Specifically, more studies focused on the epidemiology of stroke, stroke knowledge, recognition, and emergency response, hyperacute and acute care, post-stroke care, quality and cost of stroke care, and stroke outcomes are still needed.

\section{AUTHOR CONTRIBUTIONS}

PW and SG contributed equally to the conceptualization, study design, data extraction, analysis, and interpretation of the study findings. All authors critically reviewed, read, and approved the manuscript.

\section{SUPPLEMENTARY MATERIAL}

The Supplementary Material for this article can be found online at: https:/www.frontiersin.org/articles/10.3389/fneur. 2021.785607/full\#supplementary-material

3. Owolabi MO, Akarolo-Anthony S, Akinyemi R, Arnett D, Gebregziabher M, Jenkins C, et al. The burden of stroke in Africa: a glance at the present and a glimpse into the future. Cardiovasc J Afr. (2015) 26(2 Suppl 1):S2738. doi: 10.5830/CVJA-2015-038

4. Walker RW, Viney R, Green L, Mawanswila M, Maro VP, Gjertsen C, et al. Trends in stroke admissions to a Tanzanian hospital over four decades: a retrospective audit. Trop Med Int Health. (2015) 20:12906. doi: 10.1111/tmi.12547

5. O’Donnell MJ, Xavier D, Liu L, Zhang H, Chin SL, Rao-Melacini P, et al. Risk factors for ischaemic and intracerebral haemorrhagic stroke in 22 countries 
(the INTERSTROKE study): a case-control study. Lancet. (2010) 376:11223. doi: 10.1016/S0140-6736(10)60834-3

6. Ekeh BC. Challenges of the management of stroke in Sub Saharan Africa: evaluating awareness, access and action. J Pediatr Neurol Med. (2017) 02:128. doi: 10.4172/2472-100x.1000128

7. Campbell BC, Meretoja A, Donnan GA, Davis SM. Twentyyear history of the evolution of stroke thrombolysis with intravenous alteplase to reduce long-term disability. Stroke. (2015) 46:2341-6. doi: 10.1161/STROKEAHA.114.007564

8. Oleribe OO, Momoh J, Uzochukwu BS, Mbofana F, Adebiyi A, Barbera T, et al. Identifying key challenges facing healthcare systems in africa and potential solutions. Int J Gen Med. (2019) 12:395-403. doi: 10.2147/IJGM.S223882

9. Nakibuuka J, Sajatovic M, Nankabirwa J, Ssendikadiwa C, Furlan AJ, Katabira E, et al. Early mortality and functional outcome after acute stroke in Uganda: prospective study with 30 day follow-up. Springerplus. (2015) 4:450. doi: 10.1186/s40064-015-1252-8

10. Baatiema L, Chan CKY, Sav A, Somerset S. Interventions for acute stroke management in Africa: a systematic review of the evidence. Syst Rev. (2017) 6:213. doi: 10.1186/s13643-017-0594-4

11. Urimubenshi G, Cadilhac DA, Kagwiza JN, Wu O, Langhorne P. Stroke care in Africa: a systematic review of the literature. Int J Stroke. (2018) 13:797-805. doi: 10.1177/1747493018772747

12. Ministry of Health. Kenya Harmonized Health Facility Assessment (KHFA), 2018/2019. Nairobi: Ministry of Health (2020).

13. Herzog R, Álvarez-Pasquin MJ, Díaz C, Del Barrio JL, Estrada JM, Gil Á. Are healthcare workers' intentions to vaccinate related to their knowledge, beliefs and attitudes? A systematic review. BMC public health. (2013) 13:117. doi: 10.1186/1471-2458-13-154

14. Odour C, Keter A, Diero L, Siika A, Williams L. Stroke types, risk factors, quality of care and outcomes at a referral hospital in Western Kenya. East Afr Med J. (2015) 92:324-32.

15. Kaduka L, Korir A, Oduor CO, Kwasa J, Mbui J, Wabwire S, et al. Stroke distribution patterns and characteristics in Kenya's leading public health tertiary institutions: Kenyatta National Hospital and Moi Teaching and Referral Hospital. Cardiovasc J Afr. (2018) 29:68-72. doi: 10.5830/CVJA-2017-046

16. Kaduka L, Muniu E, Oduor C, Mbui J, Gakunga R, Kwasa J, et al. Stroke mortality in Kenya's public tertiary hospitals: a prospective facility-based study. Cerebrovasc Dis Extra. (2018) 8:70-9. doi: 10.1159/000488205

17. Kaduka L, Muniu E, Mbui J, Oduor Owuor C, Gakunga R, Kwasa J, et al. Disability-adjusted life-years due to stroke in Kenya. Neuroepidemiology. (2019) 53:48-54. doi: 10.1159/000498970

18. Ominde BS, Ogeng'o JA, Misiani MK, Kariuki BN. Pattern of stroke in a rural Kenyan hospital. Malawi Med J. (2019) 31, 50-55. doi: 10.4314/mmj.v31i1.9

19. Jowi JO, Mativo PM. Pathological sub-types, risk factors and outcome of stroke at the Nairobi Hospital, Kenya. East Afr Med J. (2008) 85:57281. doi: 10.4314/eamj.v85i12.43535

20. Muli G, Rhoda A. Quality of life amongst young adults with stroke living in Kenya. Afr Health Sci. (2013) 13:632-8. doi: 10.4314/ahs.v13i3.16

21. Ogengo JA, Olabu BO. Ischemic cortical stroke in a Kenyan referral hospital. J Mol Biomark Diag. (2015) 06:1-4. doi: 10.4172/2155-9929.1000238

22. Ogolla MM, Opemo DO. Early mobilization and physical activity improve stroke recovery: a cohort study of stroke inpatients in Kisumu County referral hospitals, Kenya. Am J Public Health Res. (2016) 4:154-8. doi: 10.12691/ajphr-4-4-6

23. Wanjiru Kingau N. Care process for stroke patients in kenya: mixed study. Health Educ Care. (2018) 3:136. doi: 10.15761/hec.1000136

24. Wairoto DK, Joseph OC, Kigamwa PA. Prevalence and nature of psychiatric morbidity in stroke outpatients in Kenyatta national hospital, Kenya. Int J Adv Multidiscip Res. (2020) 7:27-39. doi: 10.22192/ijamr.2020.07.01.004

25. Waweru P, Gatimu SM. Mortality and functional outcomes after a spontaneous subarachnoid haemorrhage: a retrospective multicentre cross-sectional study in Kenya. PLoS ONE. (2019) 14:e0217832. doi: 10.1371/journal.pone.0217832

26. Ministry of Health. 2013 Kenya Household Health Expenditure and Utilisation Survey. Nairobi: Government of Kenya (2014).

27. Girijala RL, Sohrabji F, Bush RL. Sex differences in stroke: review of current knowledge and evidence. Vasc Med. (2017) 22:135-45. doi: 10.1177/1358863X16668263

28. Gatimu SM, John TW. Socioeconomic inequalities in hypertension in Kenya: a decomposition analysis of 2015 Kenya STEPwise survey on non-communicable diseases risk factors. Int J Equity Health. (2020) 19:213. doi: 10.1186/s12939-020-01321-1

29. MoH KNBS, WHO. Kenya STEPwise Survey for Non-Communicable Diseases Risk Factors 2015 Report. First edition. Nairobi, Kenya: Ministry of Health, Kenya National Bureau of Statistics and World Health Organization (2015).

30. Kengne AP, Anderson CS. The neglected burden of stroke in SubSaharan Africa. Int J Stroke. (2006) 1:180-90. doi: 10.1111/j.1747-4949.2006. 00064.x

31. Keates AK, Mocumbi AO, Ntsekhe M, Sliwa K, Stewart S. Cardiovascular disease in Africa: epidemiological profile and challenges. Nat Rev Cardiol. (2017) 14:273-93. doi: 10.1038/nrcardio.2017.19

32. Walker RW, Jusabani A, Aris E, Gray WK, Mitra D, Swai M. A prospective study of stroke sub-type from within an incident population in Tanzania. $S$ Afr Med J. (2011) 101:338-44. doi: 10.7196/samj.4511

33. Goldstein LB. Stroke in sub-Saharan Africa: an urgent call for prevention. Neurology. (2013) 81:403-04. doi: 10.1212/01.wnl.0000432935. 60352.a4

34. Chin JH. Stroke in sub-Saharan Africa: an urgent call for prevention. Neurology. (2012) 78:1007-8. doi: 10.1212/WNL.0b013e318248df95

35. Kenya Medical Practitioners Dentists Council. Licenced Local Specialist Practitioners for the year 2021 as at 23/02/2021 [Online]. Nairobi: Kenya Medical Practitioners and Dentists Council (2021). Available online at: http://kmpdc.go.ke/Registers/Specialist_Practitioners.php (accessed February 22, 2021).

36. Mutua J, Wamalwa N. Leasing of Medical Equipment Project in Kenya: Value for Money Assessment. Africa Portal (2020).

37. Ministry of Health. Kenya National Strategy for the Prevention and Control of Non-Communicable Diseases (NCDs) 2021-2025. Nairobi, Kenya: Ministry of Health, Kenya (2021).

38. Walker RW, Jusabani A, Aris E, Gray WK, Whiting D, Kabadi G, et al. Poststroke case fatality within an incident population in rural Tanzania. J Neurol Neurosurg Psychiatry. (2011) 82:1001-5. doi: 10.1136/jnnp.2010.231944

39. Chao B-H, Yan F, Hua Y, Liu J-M, Yang Y, Ji X-M, et al. Stroke prevention and control system in China: CSPPC-Stroke Program. Int J Stroke. (2021) 16:265-72. doi: 10.1177/1747493020913557

Conflict of Interest: The authors declare that the research was conducted in the absence of any commercial or financial relationships that could be construed as a potential conflict of interest.

Publisher's Note: All claims expressed in this article are solely those of the authors and do not necessarily represent those of their affiliated organizations, or those of the publisher, the editors and the reviewers. Any product that may be evaluated in this article, or claim that may be made by its manufacturer, is not guaranteed or endorsed by the publisher.

Copyright (C) 2021 Waweru and Gatimu. This is an open-access article distributed under the terms of the Creative Commons Attribution License (CC BY). The use, distribution or reproduction in other forums is permitted, provided the original author(s) and the copyright owner(s) are credited and that the original publication in this journal is cited, in accordance with accepted academic practice. No use, distribution or reproduction is permitted which does not comply with these terms. 